\title{
Football Manager: Mutual Shaping between Game, Sport, and Community
}

Alexandre Hocquet Université de Lorraine \& CNRS

\begin{abstract}
Football Manager is one of the most popular sports management video games. For twenty years now, it has been a best seller in all the countries of the world where football is culturally important. Its purpose is to simulate a manager's career with an emphasis on data analysis and number crunching, especially the football match scenario and the football players' quantified characteristics. The claimed realism of the game is therefore based, among other things, on the reliability of a constantly-updated database of hundreds of thousands of real football players. The community of gamers, organized in forums and networks around the world are de facto involved in a co-construction of a database which no organization would be able to set up. Yet, Football Manager is also a piece of commercial software, and a performative computer model in the football world: its database is becoming a key issue in the real life football world and this issue provokes debates and tensions in the gaming community. As Big Data is becoming a techno scientific promise in the football world, Football Manager's metrics and database are becoming increasingly entangled in an economically growing world of real life football and data.
\end{abstract}

Keywords: sport games, modelling, sport database, game economy 


\section{Introduction}

The Football Manager series was created in the early nineties under the name Championship Manager. It has since been outstanding in terms of sales in the Personal Computer gaming industry (Nakrani, 2013), in terms of cultural impact in the UK, and by extension, around the world, in every country where football is a major cultural topic. The game tries to mimic the professional career of a manager in football in both its tactical aspects of managing a team match after match, season after season, but also in its economic and human aspects (like building a relationship to manage with the press, players, agents or club boards). ${ }^{1}$ Historically, it has quickly become one of the top selling games for the Personal Computer, and it still is twenty years later, for every yearly release.

Its success is all the more significant that it belongs to a fringe genre in two ways: the sports management genre does not resemble the games ranking high in the sales charts, and neither does it resemble most sports games, both from a narratological and a ludological perspective (Crawford \& Gosling, 2009). In particular, the graphical interface is not a crucial element of the game, or better said, the user interface favors a rendering that is opposite in aesthetics to most video games, and sports games in particular. The gameplay looks more like the management of spreadsheets than an immersion into graphical narratives. In this sense, the immersion in the game almost looks more like that of a board game than that of a video game, as described in Garry Crawford's sociological study (Crawford, 2006). Football Manager gameplay consists in large parts in performing some "number crunching" not only for the software itself, but also for the gamer, who handles quantified characteristics of players, performance statistics of the players during matches, financial figures, etc.

Beyond the actual sales figures, Football Manager is also a remarkable cultural phenomenon in the English-speaking world, particularly from the perspective of gamer communities. Forums, blogs and sites about the game are legion, and the growth in the community has been remarkable for an essentially one-player gaming experience, in an era of massive games online (Zabban, 2009).

\footnotetext{
${ }^{1}$ In this paper, the word football refers to football association, or soccer. 
As a game which belongs to the sports club management genre, the purpose of Football Manager is not to simulate a football match, unlike the FIFA or Pro Evolution Soccer series. Its aim is to model a manager's career in football. The gamer avatar is thus not the football player. It rather impersonates the paternalistic (but not omnipotent) character of the manager taking over. It is thus different from the "avastar", the charismatic, predefined personality imported from the football world (Conway, 2014). To pursue Conway's Weberian analogy, the manager avatar is more akin to a rational or legal authority.

According to Crawford, the gamer's relationship with the game is also based on intertextuality (pundits comments, simulations of interviews, scripted dialogues with players, fellow managers, coaching staff, football agents, journalists...). This intertextuality relies on the understanding of texts in the game which require an understanding of football vocabulary, not only the football which is played on the pitch, but also football as it is described in the media (Crawford, 2006). From this point of view, the experience of cultural immersion is even greater if obviously the gamer is familiar to football not only as a game, or sport, but also as a culture (which, by contrast, is absolutely not necessary in football videogames like FIFA or PES). Arguably, the FIFA or PES gameplay much less simulates a football match than it simulates a television broadcast of a football match, in its aesthetics and narratology (Stein, 2013).

Crawford noted that not only football culture is essential to fully live the gaming experience, but also gamers build their sporting identity (be it the one of a fan or the one of an analyst ...) also by experiencing Football Manager in a narratological perspective. Other media like films provide only restrictive narratives to the sports fans. In contrast, sports video games in general and Football Manager in particular provide more fluid narratives, and, a wealth of information that helps construct the identity of the football fan, beyond sport itself.

Other games fill the same niche (the football club management) but their success does not compare to that of Football Manager, not only in terms of sales but also in terms of cultural impact, in terms of gamer community, and finally, and this is the purpose of this article, in 
terms of mutual influence, "mutual shaping" between the computational model of the game and the world of the actual sport, football. Football Manager is a fascinating example to analyse the relationship between "traditional" and "digital" games. There are of course important differences between sports and video games. In this paper, I present an ethnological study that sheds light on the mutual shaping between traditional football and football managing in a videogame. More specifically, I take interest in the creation and development of the player database in the Football Manager series. I argue that the gaming community can be seen as an interface between sport and video game. I will focus on the interplay between the two from the perspective of how the game is built, highlighting the role of the gamers through an analysis of their interactions on web forums and in the creation of the dabatase. This ethnography is also fuelled by actor network theory and "software studies" (Oudshoorn \& Pinch, 2005; Fuller, 2008).

\section{Methodology}

To clarify the dynamics I would like to highlight in Football Manager and in its gamer community, let's make an analogy with a video game that is actually inspired by a board game. Europa Universalis (or the games from Paradox in general) can be viewed as an attempt to model history (with a certain view, not ideologically neutral, of what history should be), and a community of gamers dedicated to the franchise has flourished, along with particularly active debates on web forums. Among other things, the members of the community propose "mods" of the game. At the beginning, the game focused on some major European powers of the modern era (Lundgren \& Bjork, 2012). When the game developed, it became possible to play remote countries (from the Sultanate of Granada to the Golden Horde). But this didn't come from an official expansion; it was the gaming community, through the fans' mods, who integrated such countries in the gameplay, fuelling the corresponding scenario with historical events to be implemented in the game. Europa Universalis is an example of a video game intended to be a simulation (of European history from the 16th to the 18th century), whose exhaustive deterministic ambition is co-constructed by the gamer community through the game forums. Furthermore, the same forums which describe these mods are also the places where the ontology of the game as seen by the community is debated, and also its epistemology, particularly the issue of teleological

Kinephanos, ISSN 1916-985X 
determinism or contingency in the gameplay.

My interest for Football Manager is in a similar perspective regarding the database of football players, but in this case it is not a mod of the code that is at stake. It is the database of the game itself, as the artefact that is supposed to warrant the game realism. From a methodological point of view, my corpus consists in the web forums of the Football Manager community, where the gamers debate. This is a kind of "online ethnography” as defined by Christine Hine (2000), in the sense that I am studying a community of gamers, or more accurately, the small subgroup of gamers who are interested in building the game's database (the so-called "researchers") and participating in its construction (in a sense it is a coconstruction, but the following paragraphs show how the word "co -construction" as borrowed from the actor-network theory can be considered relevant or not). This is a form of participant observation of the debates, which I also used in the study of other corpora (Hocquet, 2013). Two key aspects of mailing lists or web forums (or many other forms of "threaded conversations") are relevant to highlight the debates and tensions within a community.

First, from a linguistic point of view, e-mailing or forum posting has been described as a "quasi oral" form of expression, quite different from the formality of written language, although it is technically a socio-technical device which uses computer-mediated writing, and not speaking (Beaulieu \& Hoybye, 2011). But quasi orality is not just informality. It is also an attempt to recreate the sense of community, a place where many people can exchange, something impossible in written language (Hert, 1999). The threaded conversation, according to the dramaturgical approach of Goffman (Goffman, 1959), is a place resembling the "backstage", a place where forum participants interact within the community to act without an audience (the public of a conference, the readership of a manuscript), behind the scenes, unlike onstage where they have to perform in front of the audience. Backstage is not synonymous to a "private space", it is actually quite public. Especially, according to Goffman, backstage is where the performance of the play is prepared.

The other argument is that the topics of the forums operate in heated debates or arguments.

Kinephanos, ISSN 1916-985X 
These tensions are rather negative for the health of a mailing list or web forum, but, from an analytical perspective, when conversations turn into dreaded "flame wars", they become interesting as they reveal, through their heated debates, the tensions within a community. Since debating is possible and even encouraged if it is not considered off-topic by moderators, then the most controversial tensions within the community do generate interesting threaded conversations where a variety of actors within the community can interact. It is even a way to identify the most fruitful conversations from the perspective of the debate. Just as the "scientific controversy" is a useful tool for STS to learn about the scientific, political and social issues at stake, "flame wars" are a valuable source of information. If some of the forum members appear as "trolls", i.e. provocateurs whose aim is to disrupt the harmony of the community by posting controversial topics, I borrow from Gabriella Coleman the idea that they require the community to react: the trolls' provocations allow the community to discuss and debate on sensitive issues, forcing members to leave neutral and polite stances and take position (Coleman, 2012). My methodological point is thus that the use of forums, or threaded conversations in general share the fact of being particularly suited to the controversial studies of tension situations. Furthermore, the structure of the threaded conversations in web forums provide useful insight in corporate strategies and users' interactions regarding the software or database. They translate the issues into an arena where the corporate actors (marketers, community managers, support teams, head researchers...) and different kinds of gamers/users (casual or hardcore, testers, researchers...) interact. We will discuss these elements further in another section through the concept of "software generification".

I conducted this ethnographic study on the forums of Sports Interactive, the publisher of Football Manager. ${ }^{2}$ It consists in a participant observation of a dozen years, between 2002 and 2014, completed by an intermittent role in a team member of "researchers" and beta tester. The forum is an "official" forum, in the sense that it is maintained and moderated by a team who is employed by the company. The moderation of messages, in particular, is part of a policy defined by the company, even if freedom of expression on the forum allows much criticism of the game itself, and also of the publisher's policies. Typically for a web forum, it

\footnotetext{
${ }^{2}$ http:// community. sigames. com/

Kinephanos, ISSN 1916-985X 
is divided into hierarchical topics. A sub forum is entirely devoted to the database construction and is accessible to all gamers and is categorized by football clubs and regions. Private forums also exist for "researchers", especially for harmonizing the data which are offsight to the community as a whole.

As in any ethnography conducted online, the question of the representativeness of the forum in the community is twofold. First, the question arises as to what extent the community who is voicing their concerns on the forums is representative of the forum community as a whole, and even the community of gamers as a whole. The observation of controversies on forums provides a methodological answer to this question: the tension related to the controversy forces the actors to argue. Indeed, the most important points of view (or world views) are represented in these debates, even though they are not necessarily an accurate statistical representation of all the "lurkers" (i.e. the silent crowd).

There is also the translation issue: how similar or different are the community's interactions within the forum to the community's interactions outside the forum? In our case it is the evolution of the database itself over time which translates the tensions within the forum in terms of "gameplay": the forum provides a representation of how the game is evolving, and vice versa. In the next section, I will present the modelling principles that have guided the creation and development of the database, and the role of the community within it.

\section{Epistemology}

Football Manager's gameplay is based not only on a culture, but also on an epistemological model. The avowed aim of Football Manager is to simulate reality, or, more precisely, its very own vision of what is a realistic career of a manager. Its ambition is deterministic or even naively positivist: football players are modelled and quantified with features akin to the characters in role-playing games, football matches scores are resolved by systems of equations involving the highest possible number of parameters, and the game is indeed highly demanding in terms of computational power. The view of what is realism according to Football Manager resembles the work of an analyst more than it is a tracksuit job. Even 
though the interactions with players or agents or press conferences are simulated, the interactive part more often than not makes way to deterministic simulations of matches statistics, or player characteristics evolutions, or in a nutshell: number crunching.

From the simulation point of view, Football Manager thus possesses an almost positivist epistemological ambition. Within this framework, the game wants to translate the world of football into numbers, and especially to simulate positivistically the football's most iconic moment: the match. It relies on a so-called "game engine" which aims to reproduce, in a highly deterministic fashion, the ninety minutes of the football match from calculated movements based on the maximum amount of characteristics from the players' performance styles.

The concern for realism is all the more pivotal because the players (but also the clubs, leagues, coaches, etc ...) are supposed to be described as accurate quantitative representations of real players, thanks to characteristics translated into numbers, in a similar way to roleplaying characters. ${ }^{3}$ That is to say, the model seeks to be the best possible translation of a football player style of play and physical, technical and mental traits into numbers. The ambitious realism of the game is therefore based, among other things, on the reliability of a database of hundreds of thousands of real football players (some of whom are playing football in obscure championships with very low media access) and this database is constantly being updated.

The credibility issue in the representation of reality relies heavily on "naming" rights which are negotiated with the sports federations. These contracts are often exclusive: if a game (like FIFA) gets the license to give the real names of players and clubs, its credibility is strengthened, and the credibility of its competitors (such as PES) reduced accordingly. The cost of the annual licensing policy of athletes' names is actually the very reason for the high entry cost in the video sports gaming industry, and the reason for the sales strategy to establish a recurring yearly edition of the video game, to afford the cost for the yearly

\footnotetext{
${ }^{3}$ Throughout the text, I am naming "players" the real life football players, and "gamers" the Football Manager players who incarnate managers, in order to avoid confusion.
} 
licensing expenses. But in the case of Football Manager, the issue goes beyond "real name" credibility. A football player character in Football Manager should reproduce its real life model as closely as possible with quantitative characteristics (Todd, 2014). This is mandatory for the sake of gameplay, unlike football games like FIFA or PES.

To achieve this, the football player's quantified characteristics are supposed to depict his skills, preferred moves, his physical traits like speed or fitness, but also personal traits like ambition, professionalism and so on. In the early nineties, the sum of all players represented in the game reached hundreds, all well-known to people familiar with football culture. It is now filled with hundreds of thousands of players, the vast majority being completely unknown to any professional football specialist. This means that this essential element of the game (as a warrant of the realism of the simulation) soon escaped the expertise of the developers' team, even though the team rapidly became a professional one along with media coverage and financial success. ${ }^{4}$ The consequence is that the database of football players is the bedrock of the whole game experience and cannot be fed as comprehensively (regarding the number of real life players involved) and as broadly (geographically) without involving the gaming community.

The community of millions of gamers, organized worldwide in forums and networks of socalled "researchers" participate de facto in the co-construction of a database that no organization would be able to set up. The database of the Football Manager players is thus crowdsourced. In this regard, the Football Manager forums show an operational form of organization which looks like organizations based on a "commons" philosophy, an "adhocracy" typical of the world of free software communities or Wikipedia. But, contrary to the latter, Football Manager is a commercial piece of software with a proprietary license. It is also the flagship product of a company with sales targets, for which the database is a key issue. It is the active community of gamers who is in charge, under the hierarchy of the publishing company of the game, and through the forums set up by the latter. "Head researchers” are casted and then appointed by geographic and "footballistic” divisions; they

\footnotetext{
${ }^{4}$ The Sports Interactive development company, backed by a worldwide distribution partner, became a solid game creation studio within a few years)

Kinephanos, ISSN 1916-985X 
recruit "researchers" in the community or contacts on football fan forums. This represents a global grid from Hong Kong to Weston-Super-Mare that no specialist in football can reach, be it a journalist, be it a "scout" (i.e. an employee of a football club who works as a talent detector) or be it a player's agent. This also represents a deep knowledge of the players, and a collective one, a "wisdom of the crowds" guaranteed by hundreds of fans attending the matches of reserve or youth teams of their favorite club, producing superior expertise in some cases to the very own coaching staff of the club itself (Bleaney, 2014b). Arguably, it also represents a form of "digital labor", that is to say, the use by the corporation of the labor by a crowd of enthusiast and organised gamers/consumers to produce value with no or feeble reward, according to a Marxist point of view (Scholz, 2013).

\section{Generification}

As we saw in the previous section, tensions arise between two different Weltanschauungen: on the one hand, a community co-constructing a crowdsourced database and on the other, a corporation operating a database with a growing financial impact at stake. This materiality of modeling will be analyzed here through the prism of "software generification", a concept developed by Pollock and his coworkers (Pollock, Williams, \& D'Adderio, 2007).

In their initial study, Pollock et al. were interested in the relations between users and software from the point of view of Science \& Technology Studies. Their point was to study "marketoriented" software strategies to manage its user community, and their case study was about the development of organizational software for large companies (Pollock et al., 2007). They studied how the software evolved in its customer acquisition process. Their aim was not to describe the appropriation of software by local users (the so-called "user driven innovation”), but rather the way the software was shaped so that it could be used (and sold) as widely as possible. They called this process "software generification".

In the world of science, I emulated their idea and applied the concept to scientific modeling software, highlighting the tensions that these "market-oriented" software strategies caused on issues such as scientific reproducibility, or more generally how the software in a certain 
technological, economic or political context came to change the way of doing science, and changed the way to produce knowledge (Hocquet, 2013).

The process of generification, according to Pollock et al., is not just a tendency to become a more versatile program to gain market shares. It consists in mechanics that involve molding the users' community. The authors call it "community management" to describe the fact that the evolution of the software requires the enrollment of initial users who will form the basis on which software developers count, resulting in excluding the rest of the users from the software development process (the rest being the majority of the later users, or the less involved ones). The idea is to build a community of users (with different roles) and to shape it so that the said community corresponds to the capabilities of the software as closely as possible. In a process of mutual shaping, the "first layer" of users will try to tailor the software to their specific needs. The community management therefore consists in relying on a small fraction of users (early users, or lead users, or more involved users) to keep the vast majority of them, the "outer layer" of users, away from the issues at stake.

The concept of software generification has been introduced by its authors to describe strategies developed by the software industry to shape their user/client community into adopting their evolving piece of software. Clearly, these ideas can be applied into the construction of the database part of the Football Manager video game. The constitution of the database is the real stake in the development of the series. The database was built through the gamer community and this is still the case up to this day; this "crowdsourcing" is more effective than any other method of scouting, even compared to powerful economic structures. But the economic and cultural stakes of the privately-owned database imply that the management of the community, similar to the one that Pollock et al. describe, leads to many tensions, and a growing frustration among gamers.

As I have noted above, the database has been crowdsourced to a large extent. From the perspective of "hardcore" gamers, the task is not only taken seriously (since credibility is essential to the gameplay), but it is even a rewarding task, because each gamer has a sense of playing a part in the construction of the world in which he or she plays. These first hardcore 
gamers soon became wannabe researchers, that is to say, a kind of lead users who acquired some status both in the web forums but also in the database bureaucracy. According to the idea of "software generification", these gamers formed a first shell of users, the one that is enrolled by the software to co-construct the database.

The construction of the database is debated within the community forums, but the organizational structure is formal and is in practice defined by Sports Interactive. For each club in England, each country in Europe, each continent in areas where football is poorly covered in the media, a "head researcher" is officially named. It is often a historical member of the community who won credibility through his or her interactions on the forum, like a Wikipedia editor or other forum driven communities. Each "head researcher" is then supposed to organize his or her network of informants, the so-called "researchers", by finding them either directly on the forums of the game or on the football fans' forums of a given club. "Researchers" are required to possess an exhaustive knowledge of the football club for which they are applying. Watching all club matches, if possible at the stadium rather than on TV and being aware of the club news, is a minimum. Watching reserve and youth teams matches is a guarantee of reliability. In all cases, a thread on the forum is open for every club, open to debate, in which the "researcher" is supposed to answer to questions or suggestions, to permit the co-construction of his or her database part with the rest of the community.

The hierarchical organization of "researchers" is not quite an "adhocracy” like Wikipedia. It rather resembles a pyramid structure. It is built on debate, but the roles are formal with "head researchers” topping "researchers”. "Head researchers” are oftentimes experienced gamers that gained status to become specialized in a club or a nation. They can be rewarded with actual wages or are even officially employed by the company. They represent the "inner shell” of users. By comparison, “researchers” are volunteers, and receive only small material rewards (a free copy of the game from time to time). Their experience of the forum debates can be uncomfortable at times when their skills or knowledge are challenged by the community. Discussing football players' abilities is an eternal theme of armchair debating, punctuated with aggressive conversations and the "Researcher" is often to be found in the front line.

Kinephanos, ISSN 1916-985X 


\section{A performative database: reinvesting sports}

In recent years, the success of the realism of the database (parallel to the commercial success of the series) reached the point when striking examples of real-life football players, unknown not long before, became football stars a few years after Football Manager had predicted they would rise to worldwide fame (Nakrani, 2013). Obviously, there are also a lot of "future star" wonderkids in Football Manager who eventually turn into anonymous limited players in real life. Sometimes they even reach the status of famous anti-hero in the gaming community (Ames, 2015). But these striking examples of success (Lionel Messi is often cited) are enough to give Football Manager a credibility that goes beyond the gaming world and begins to be recognized in the real life football world. Within a few years, the quality of the database has become predictive. Some players who blossom in the real world appear to have been notorious "wonderkids" in former versions of the game, even before they get modestly renowned in real life. This is the first performativity of the game. In the mid-2000s, it was suspected that football clubs in real life did sign young players on the basis of the Football Manager database. Nowadays, clubs do admit it openly (Stuart, 2014).

Meanwhile and parallel to this, the "Big Data" hype is spreading gradually in real life football. Corporate companies flourish that are in the business of offering metrics to evaluate players based on data collected during the matches, in order to describe the players quantitatively. A situation arises that Joly describes as a "techno scientific promise" regime related to a market (Joly, 2013): the transfers of football players in real life are numbered in tens of millions of euros, and the business is based on an opaque rationality. Clubs scouting departments become fonder and fonder of number crunching in the hope of rationalizing investments in players. Moreover, the flourishing industry of sports betting is increasingly paying attention to football metrics definitions. There is an enormous global financial challenge at stake. In this field, there is a sport in the USA which has paved the way and this "technological promise” originates in its anterior media success. Baseball, unlike football (Obœuf, Collard \& Pruvost, 2009), is a sport which readily accommodates with "number crunching”, statistical processing and the definition of mathematical parameters which describe the game. In the United States, baseball culture is closely linked to this 
quantification. It even has its heroes and its Hollywood success story. The Moneyball book (and subsequent movie) tells the story of Billy Dean as a "Big Data” baseball prophet (Lewis, 2004). In the world of football, "number crunching” is still in its infancy: On the one hand, the world of football is enthralled by the "technological promise" of its proselytes from the world of baseball (Phillips, 2011). ${ }^{5}$ Moreover, some companies are created to collect data and devise metrics to monetize this promising market, but the maturity of the said metrics is still to be reached or even defined, unlike the situation in baseball (Ingle, 2014).

It is in this context that the first performative successes of Football Manager appear. Football Manager metrics are inspired by football matches but also by their television broadcasts. The popularity of gaming metrics is such that they do influence in turn how to define the metrics of the companies which collect data in real matches in order to create real football metrics (Stuart 2014). To the point that the boundaries between football metrics and metrics of the game are blurred (Bleaney, 2014A). This is the second performativity of the game. Like the first, it is the result of mutual influence between the football world and the gameworld in Football Manager.

Some transfers of players in real life become notoriously influenced by the game: the database becomes a trade asset that exceeds the one of the game. It has been recently released that the powerful English football club Everton did pay, via an exclusive contract with Sports Interactive, to access the database before the annual release of the game (Daily, 2008), in order to take advantage of signing players on the market. The database is thus involved in a business of its own, a bigger business at stake than the game itself in the real world.

Heated debates in the forums are predictably concerning diverging opinions regarding players performances, styles, or attitudes. Beyond the mere appreciations of a player performances on the pitch compared to his avatar in Football Manager, one of the core issues is the predictivity of future success for today's younger players. In other words, given the importance of the database as a predictive tool on the real football market, the issues are not

\footnotetext{
${ }^{5}$ Especially since big English football clubs are owned by American tycoons, the case of Liverpool $\mathrm{FC}$ is notorious.
}

Kinephanos, ISSN 1916-985X 
only in the adequacy of the simulating tool to emulate real football but in its predictivity. A recurring debate is the tension, for a given young starlet performing surprisingly well in real life (think about, for the 2015/2016 season, the likes of Dele Alli or Marcus Rashford, or conversely, the 2015/2016 season of Jack Grealish as compared to his 2014/2015 performances), between adjusting characteristics (and level) of the avatar player to suit as accurately as possible to the perceived (and covered in the media) performances of the newly introduced first teamer, or, sticking to a long term policy of letting the avatar player develop ingame just as its calculated ability and future development had been assessed with the previous observation of his youth or reserve matches. In other words, there is a tension between adaptability of the modelling versus its consistency.

This dilemma is even more striking when it comes to a player that is transferred from a country to another, particularly when his new club plays in a league where media coverage is high. In database terms, this player has officially transferred from a head researcher to another, and by doing so, he enters a new culture of assessment of his characteristics. The new 2015/2016 West Ham star, Dimitri Payet, is debuting in the Premier League this season, and he receives a completely different media attention and his way of playing is discovered by a new team of researchers/gamers. How such a gifted player could have been so undervalued until now? Because Dimitri Payet was playing in the less covered Ligue 1, even though he had even better statistics, and players from this league are not evaluated within the same framework. Moreover, Payet has played in France with four different clubs under many different coaches. Beyond issues regarding his perceived ability and skills, his style of play has changed over the guidance of different coaches, and debates are still heating on his preferred position (winger in St Étienne, central playmaker in Marseille, again playing wide at West Ham...). Assessments in the English and French research teams are not the same, not only in perceptions of player's levels but also culturally in perceptions of players styles of play.

More globally, throughout the history of Football Manager some countries (meaning: some researcher staffs under the guidance of a head researcher) have been notoriously overvalued or undervalued, but it is quite recurrent that British football is considered the genuine

Kinephanos, ISSN 1916-985X 
reference in Football Manager terms. Not so much because of a supposed cognitive bias towards players and teams and countries, but because the vast majority of the game designers is British, and the Football Manager culture as described by Crawford is essentially a British culture (even though it is a globalized one), many aspects of the game (league and club structures, staff, media coverage) are thought and designed as such. There is thus a difficulty to translate some aspects of the game into different countries where competition structure or youth infrastructure does not fit into British terms.

One of recent tensions involves the system of evaluation of club youth academies (a pivotal issue since it has an influence upon how new breed of players are generated season after season). Researchers in non-British countries have to adapt to model the youth structure of the leagues in their countries to a set of guidelines designed by the company based on the assessment of English Premier League structure, and those guidelines, once discussed in the community are now kept secret and only head researchers have access to them. They are furthermore imposed on them and the possibility of feedback is very scarce. Not unlike Dimitri Payet's case, the issue of translating a player (or any game aspect) from one league into another is a typical issue that is more and more escaping the community itself.

The consequence in the world of the Football Manager community is that volunteer "researchers" are increasingly excluded from the process of mathematization of the players. Meanwhile, a pseudo professionalization of the "head researcher" job is organized within Sports Interactive. A culture of secrecy within the forums settles. On the other hand, these researchers are still pivotal since no other structure could be as successful as the community in building the database. Tension is increasing in the debates concerning the database in the forums. In the Europa Universalis modding community, gamers are free to include the mods in the game or not. Paradox merely provides an opportunity for the community to intervene in the gameplay. In Football Manager, the construction of the database is a vital issue not only for the game itself, but it has also become an important issue in the world of traditional football, a world of impressive financial stakes. In a world of monetized Big Data, the company foresees that a fair amount of its revenues will soon come from the database itself rather than the game.

Kinephanos, ISSN 1916-985X 
The "community management" part of the "software generification" process has thus been more and more difficult over the years, as the economic importance of the database rose, and the exclusion of "outer shells" of users turned into tensions between the researchers and the hierarchy. The increasing importance of the Football Manager database in the real football economy is thus, according to the "software generification" concept, the driving force leading to the community management that consists in excluding "outer shells" of users.

\section{Conclusion}

The mutual shaping highlighted in our study is twofold: between the metrics of the Football Manager game and sport, and between the Football Manager software and the community of gamers. These mutual shapings are prone to tensions in the community. These tensions express the fact that the Football Manager issues are not only gaming concerns, but are also sport concerns both economically and culturally. The process of "software generification" describes these tensions as a difficult relationship between the software and its users.

\section{Works cited}

AMES, N. (2015, July 22). "Cherno Samba retires after modest career but as a Championship Manager legend”, The Guardian. Retrieved from

http://www.theguardian.com/football/blog/2015/jul/22/cherno-samba-championshipmanager-retires-millwall-plymouth

BEAULIEU, A., \& HØYBYE, M. T. (2011). "Studying Mailing Lists: Text, Temporality, Interaction and Materiality at the Intersection of Email and the Web”, The Handbook of Emergent Technologies in Social Research, 257.

BLEANEY, R. (2014a, August 11). "Football Manager computer game to help Premier League clubs buy players”, The Guardian. Retrieved from

http://www.theguardian.com/football/2014/aug/11/football-manager-computer-game-premierleague-clubs-buy-players

BLEANEY, R. (2014b, August 28). "Bafétimbi Gomis: I researched Swansea on Football Manager computer game”, The Guardian. Retrieved from http://www.theguardian.com/football/2014/aug/28/bafetimbi-gomis-football-managercomputer-game-swansea-city-lyon

COLEMAN, G. (2012). "Phreakers, Hackers, and Trolls: The Politics of Transgression and Spectacle”, in M. Mandiberg (Ed.), The social media reader (pp. 99-119). New York: New York University Press. Retrieved from http://site.ebrary.com/id/10535662 
CONWAY, Steve. (2014). “Avastars: The Encoding of Fame within Sport Digital Games”, In T. P. Oates \& R. A. Brookey (Eds.), Playing to Win: Sports, Video Games, and the Culture of Play (pp. 133-151). Bloomington: Indiana University Press.

CRAWFORD, G. (2006). "The cult of Champ Man: the culture and pleasures of Championship Manager/Football Manager gamers”, Information, Communication \& Society, 9(4), 496-514.

CRAWFORD, G., \& GOSLING, V. K. (2009). "More Than a Game: Sports-Themed Video Games and Player Narratives”, Sociology of Sport Journal, 26(1).

DAILY, R. (2008, November 14). "Everton sign deal to scout for world's best players in Football Manager video game”, Dailyrecord. Retrieved from http://www.dailyrecord.co.uk/news/uk-world-news/everton-sign-deal-to-scout-for-worlds997789

FULLER, M. (2008). Software Studies: A Lexicon. The MIT Press.

GOFFMAN, E. (1959). The presentation of self in everyday life. Doubleday.

GODODMAN, M. (2014, November 9). “The Adolescence of Soccer Stats”. Retrieved from http://grantland.com/the-triangle/the-adolescence-of-soccer-stats/

HERT, P. (1999). “Quasi-oralité de l'écriture électronique et sentiment de communauté dans les débats scientifiques en ligne”, Réseaux, 17(97), 211-259.

http://doi.org/10.3406/reso.1999.2171

HINE, C. (2000). Virtual ethnography (Vols. 1-1). London, United Kingdom.

INGLE, S. (2014, October 17). “Billy Beane can’t get enough of soccer after revolutionising baseball”, The Guardian. Retrieved from http://www.theguardian.com/sport/2014/oct/17/billy-beane-soccer-baseball-oakland JOLY, P.-B. (2013). “On the economics of techno-scientific promises”, in M. Akrich, Y. Barthe, F. Muniesa, \& P. Mustar (Eds.), Débordements : Mélanges offerts à Michel Callon (pp. 203-221). Paris: Presses des Mines. Retrieved from http://books.openedition.org/pressesmines/747

LEWIS, M. (2004). “Moneyball: The Art of Winning an Unfair Game” (1st edition). New York: W. W. Norton \& Company.

LUNDGREN, S., \& BJÖRK, S. (2012). “Neither Playing nor Gaming: Pottering in Games”, in Proceedings of the International Conference on the Foundations of Digital Games (pp. 113-120). New York, NY, USA: ACM. http://doi.org/10.1145/2282338.2282363

NAKRANI, S. (2013, August 13). "Football Manager craze has matured into a full-grown national obsession”, The Guardian. Retrieved from http://www.theguardian.com/football/blog/2013/aug/21/football-manager-craze-lionel-messi

OBOEUF, A., COLLARD, L., \& PRUVOST, A. (2009). "La prévisibilité au service de l'imprévisibilité. À la recherche du « code secret » du football”, Réseaux, n 156(4), 241270. http://doi.org/10.3917/res.156.0241

OUDSHOORN, N., \& PINCH, T. (Eds.). (2005). How Users Matter: The Co-Construction of Users and Technology. Cambridge, Mass.: The MIT Press.

Kinephanos, ISSN 1916-985X 
PHILLIPS, B. (2011, January 27). “Numberless Wonders”, Slate. Retrieved from http://www.slate.com/articles/sports/sports_nut/2011/01/numberless_wonders.html

POLLOCK, N., WILLIAMS, R., \& D’ADDERIO, L. (2007). “Global Software and Its Provenance: Generification Work in the Production of Organizational Software Packages”, Social Studies of Science, 37(2), 254-280.

SCHOLZ, T. (2013). Digital Labor: The Internet as Playground and Factory. Routledge.

STEIN, Abe. (2013). "Playing the game on television”, In M. Consalvo, K. Mitgutsch, \& A. Stein (Eds.), Sports Videogames (pp. 115-137). Routledge.

STUART, K. (2014, December 8). "Why clubs are using Football Manager as a real-life scouting tool”, The Guardian. Retrieved from

http://www.theguardian.com/technology/2014/aug/12/why-clubs-football-manager-scoutingtool

TODD, O. (2014, June 21). "Paul Pogba picks himself in Chelsea's midfield on Football Manager”, The Daily Mail. Retrieved June 22, 2014, from

http://www.dailymail.co.uk/sport/football/article-2664580/Paul-Pogba-likes-look-Chelseashirt-picks-Blues-midfield-Football-Manager.html

ZABBAN, V. (2009). “Hors jeu ?”, Terrains \& travaux, n 15(1), 81-81.

\section{Résumé}

Football Manager est un jeu vidéo de gestion sportive parmi les plus populaires. Il est un best-seller depuis une vingtaine d'années dans tous les pays du monde où le football est culturellement important. Son but est de simuler de la manière la plus précise possible la carrière d'un entraîneur, et en particulier le match et les caractéristiques des joueurs. Le réalisme du jeu repose donc, entre autres choses, sur la fiabilité d'une base de données de centaines de milliers de joueurs de football réels qui est en actualisation constante. La communauté de gamers, organisée en forums et en réseaux à travers le monde participe de fait à la co-construction d'une base de données qu'aucune organisation ne serait capable de produire. Mais Football Manager est aussi un logiciel commercial, et un modèle informatique performatif dans le monde du Football, pour laquelle cette base de données est un enjeu primordial, provoquant débats et tensions dans la communauté des gamers. Dans le même temps que le « Big data » devient une "promesse techno-scientifique" dans le monde du football, les métriques et la base de données de Football Manager deviennent entremêlées dans le monde économiquement en croissance du football et des data de la vraie vie.

Mot-clés : jeux de sport, modélisation, base de données sportives, économie du jeu

Kinephanos, ISSN 1916-985X

Exploring the Frontiers of Digital Gaming: Traditional Games, Expressive Games, Pervasive Games, special issue, April 2016 www.kinephanos.ca 